\title{
Avatares de la subjetividad intelectual venezolana y del Estado comunal bolivariano en Rating (20II) de Alberto Barrera Tyszka
}

En este trabajo exploro la manera en que la novela Rating de Alberto Barrera Tyszka (Caracas, 1960) historiza la subjetividad intelectual en la Venezuela de las últimas cinco décadas (desde las vanguardias de los sesenta al presente). Mi lectura parte del análisis de una escena que considero clave (la expulsión del protagonista de la universidad y su ingreso laboral a un canal de televisión) para sugerir que la novela se articula en torno a nociones convocadas por las referencias a la universidad (cultura letrada, racionalización) y a la televisión (industrias culturales, melodrama, globalización), para explorar los ámbitos públicos (la política) y privados (afectos) de la actual sociedad venezolana y de la sociedad globalizada. Al mismo tiempo, sostengo que, a través de la elaboración de una compleja alegoría política, indaga en los orígenes del Estado moderno venezolano y en la forma que ha adquirido con la llamada revolución bolivariana, en particular la del Estado comunal.

El intento de historizar las circunstancias de la subjetividad intelectual en los escenarios de la avanzada globalización, bien puede reconocerse como parte de un melodrama real.

Hermann Herlinghaus

El Estado emanado de la "revolución bolivariana", comandada por Hugo Chávez a finales del siglo veinte, ha generado una polarización política que ha permeado todos los ámbitos de la vida pública venezolana. En la última década la división política se ha profundizado hasta crear una "cultura oficial" y una "cultura de oposición" (Torres 913). La primera ha impuesto, desde el discurso público y las instituciones culturales estatales, un imaginario social que se articula en torno a la defensa de la identidad nacional, la cultura tradicional y los grupos marginados (indígenas y 
afrodescendientes, principalmente). En términos ideológicos, ha trazado una genealogía revolucionaria que vincula el Estado con las guerras independentistas - con la figura de Bolívar, en particular - y los movimientos guerrilleros y estudiantiles de los setenta, de inspiración marxista. La “cultura de oposición”, en cambio, se asocia, de manera general, a una defensa de la libertad individual frente a las identidades colectivas del campo oficial, se articula políticamente en torno a la exigencia de democracia, en respuesta al autoritarismo del régimen, y se identifica con las industrias culturales de la sociedad globalizada (cine, televisión, prensa, etc.) como forma de escapar a las limitaciones del imaginario nacionalista bolivariano.

En este contexto de abierta confrontación política, la literatura venezolana se ha constituido en un intento por explicar el caos del presente y está siendo leída por los diferentes públicos como "una declaración referida a la situación política actual" (Silva Beauregard), lo que ha llevado a críticos como Gustavo Guerrero a definirla en conjunto

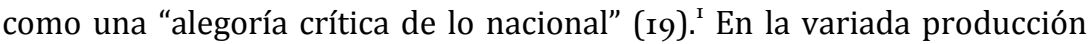
narrativa actual destacan algunas vertientes definidas que intentan resistir a las versiones de la historia, los imaginarios sociales y las construcciones identitarias que ha implantado la República Bolivariana. Como ejemplos de la indagación histórica se encuentran las novelas Los últimos espectadores del acorazado Potemkin (1999) de Ana Teresa Torres, Falke (2004) de Federico Vegas y El pasajero de Truman (2008) de Francisco Suniaga, que hacen extensas exploraciones de la tradición rural y caudillista venezolana para desmantelar el tono épico que ha asumido la revolución bolivariana y trazar los orígenes del autoritarismo actual. Los imaginarios sociales de progreso material y armonía colectiva son puestos en duda por obras como Nocturama (2006) de Ana Teresa Torres, La enfermedad (2006) de Alberto Barrera Tyszka y Latidos de Caracas (2008) de Gisela Kozak Rovero, que Miguel Gomes en un lúcido ensayo ha agrupado en lo que llama el "ciclo del chavismo", y que se caracterizan por ofrecer "amplios panoramas sociales" en los que se perciben las consecuencias del quiebre del proyecto nacional venezolano: "fábulas del deterioro" en las que emergen retratos urbanos ruinosos, una "crítica circunspecta al autoritarismo" y una imaginería nocturna que desemboca en una actitud introspectiva ("Modernidad" 823). Finalmente, la obra narrativa de Eduardo Sánchez Rugeles, en la que destaca su novela Blue label/Etiqueta azul (20IO), ejemplifica una tendencia de la narrativa escrita por jóvenes que consiste en sintonizar su lenguaje literario con las referencias culturales transnacionales para escapar a las construcciones identitarias nacionalistas y a las limitaciones expresivas de la estética socialista. ${ }^{2} \mathrm{La}$ 
crítica ha distinguido algunas constantes en las estrategias retóricas y discursivas de esta narrativa: una crítica al autoritarismo a través de la alegoría, como en el caso de La enfermedad de Barrera Tyszka, donde el cuerpo enfermo del protagonista evoca el cuerpo enfermo de la nación (Gomes, "Modernidad"); la indagación histórica a través de la sinécdoque, es decir, el examen de un periodo histórico específico para explicar toda la historia nacional (Silva Beauregard); y la recreación y adopción de estéticas del pasado que han servido para definir la identidad nacional, de manera notable el realismo de Rómulo Gallegos (Silva Beauregard) y el estilo "expresionista" de Salvador Garmendia (Gomes, "Modernidad").

La novela Rating de Alberto Barrera Tyszka que examinaré en este trabajo participa de las preocupaciones de la narrativa venezolana actual y compendia, de manera original, las operaciones discursivas que he mencionado, pero al mismo tiempo emprende una crítica al régimen autoritario de la república bolivariana desde una perspectiva distinta a la de la novelística actual. Una de las críticas más comunes que hace el discurso político opositor y muchas obras narrativas - como Falke o Los últimos espectadores del acorazado Potemkin - del régimen chavista es la de su anacronismo histórico e ideológico. Por un lado, el protagonismo autoritario de Hugo Chávez - y de su sucesor - se percibe como una reaparición del caudillismo decimonónico, con su fuerte matriz rural; y por otro, la apropiación discursiva que hace el régimen de la militancia izquierdista de los años setenta pone en duda la pretendida propuesta de un socialismo renovado, del siglo XXI (Kozak 78). En ese trabajo sugiero que Rating explora la militancia estudiantil izquierdista de los años sesenta y setenta, el campo intelectual venezolano y los medios de comunicación con un propósito doble: en primer lugar, dilucidar la naturaleza real de la república bolivariana, no como la de un régimen anacrónico, sino como un Estado que ha asumido el monopolio comunicacional en la arena pública y ha cooptado a grandes sectores sociales, lo que en mi lectura lo acerca más al Estado espectacular-democrático que discute Giorgio Agamben ("Marginal Notes") que al caudillismo decimonónico que ve un grupo importante de críticos y narradores; y en segundo, para señalar que la militancia estudiantil de izquierda no reapareció en primera instancia en la revolución bolivariana, sino que se disolvió en la sociedad venezolana neoliberal de los ochenta y de los noventa ante la incapacidad del campo intelectual de atraerla.

A continuación presento un resumen de la trama de la novela antes de delinear más detalladamente el argumento crítico de mi trabajo. Rating tiene como protagonistas a dos hombres que se conocen en el departamento de programas dramáticos de un canal de televisión. El 
primero, Pablo Manzanares, es un joven estudiante de Letras, que ingresa a trabajar al canal. El segundo es Manuel Izquierdo, un libretista veterano, que ha recorrido todo el escalafón en el "departamento de recursos literarios" del canal: desde "dialoguista" que desarrolla las escenas concebidas por alguien más hasta libretista titular de varios éxitos de audiencia (56). Izquierdo está a punto de cumplir cincuenta años y comienza a notar las primeras señales de la vejez. Hace poco ha decidido comenzar la escritura de un diario personal en el que va registrando los leves recordatorios cotidianos de una lenta disolución que le envía su cuerpo. Ambos personajes coinciden en el último capricho de su jefe, Rafael Quevedo, el cual constituye la trama central de la novela: el diseño de un reality show con indigentes que funcione, al mismo tiempo, como una telenovela. A Manuel Izquierdo se le ha pedido que desarrolle el contenido dramático de este nuevo programa. Para este libretista, que ha sido parte de la industria sin haber tenido antes ningún reparo ético al funcionamiento y las prácticas del canal de televisión, la nueva propuesta le da la sensación de haber llegado a un límite: "Tengo cincuenta años ... Ya es hora de que me atreva a decir que no, coño" (42). Esta sensación de límite obliga al personaje a emprender una exploración intelectual y afectiva de su vida, que a su vez sirve para abrir el arco crítico que esta novela nos plantea.

Desde este aparentemente reducido ámbito del canal de televisión, Rating desplegará, a mi entender, una exploración amplia, aunque expresada de manera oblicua, de la sociedad venezolana de los últimos cincuenta años. Mi análisis sugiere que la exploración del pasado del protagonista Izquierdo permite, en un audaz movimiento crítico de la novela, resituar la herencia de la militancia de izquierda más allá del ámbito del chavismo, no para restaurarlo ni para eximirlo de culpas, sino para intentar explicar, por un lado, las dinámicas sociales que propiciaron su disolución - la emergencia de la sociedad neoliberal, principalmente - y, por otro, para replantear las consecuencias para la literatura actual del fin de la vanguardia literaria de los sesenta. Sin ser menos importante, la exploración personal del protagonista, enfrentado a la lógica del melodrama, lo llevará a redefinir sus afectos en una reacción a la tradición patriarcal, para desmarcarse del machismo alojado en los mismos medios, la tradición de izquierda y en el discurso político bolivariano. Es por esta profunda exploración del protagonista, que es a la vez afectiva e intelectual, que uso el término de "subjetividad intelectual" de Hermann Herlinghaus, que, al incluir el ámbito de lo privado, va más allá del tradicional examen de la "figura del intelectual". Al mismo tiempo, el enfoque en el canal de televisión y la producción de melodramas 
televisivos, me permitirá desplegar la alegoría política compleja que propone la novela para explicar las formas de operar del Estado comunal creado por la revolución bolivariana: en primer lugar, exploraré el vínculo entre el amor y el discurso político del chavismo y, en segundo, a partir de las referencias en la novela a la implantación de las telenovelas cubanas en Venezuela, haré un rastreo de las referencias alegóricas a la imitación del modelo político cubano, que es de donde, sugiero, se ha alimentado el régimen bolivariano, más que de la militancia izquierdista local. Concluiré con una breve discusión de la soledad final del protagonista en que escribe su diario personal y sobre las vías que esa escena de escritura pueda proponer para el campo literario venezolano del presente.

Para reconstruir el periodo histórico en que indaga la novela, asumamos como el presente de la escritura el comienzo de la década de 2000 (y hay varias referencias alegóricas al régimen chavista, como veremos), entonces los años en que Izquierdo era estudiante universitario y trabajaba en la Biblioteca Nacional era a fines de la década de los setenta. El protagonista recuerda con emoción ("Eso era fantástico" [63]) esa temporada en la que alternaba lecturas y encuentros sexuales con Moraima, una estudiante de Bibliotecología, detrás de los estantes, "envueltos en ese maravilloso y profundo olor de los libros" (63). Un día son descubiertos por un profesor y él pierde su trabajo. Fin de una utopía personal en la que convergía el amor por la literatura y el erotismo, y, que apunta, a su vez, al final de la utopía intelectual y política de la década anterior: la utopía de la izquierda letrada latinoamericana que aunaba el compromiso político (Izquierdo era después de todo estudiante de sociología que despreciaba a los estudiantes de Letras que se limitaban a la dimensión estética del arte), la literatura - en su versión de vanguardia estética - y el erotismo libre. ${ }^{3}$ Me parece que esta referencia a la expulsión del protagonista de la Biblioteca Nacional marca un hito en su vida y postula una clave para entender las dinámicas entre la subjetividad intelectual, el campo literario y la sociedad venezolana.

"DE LAS UTOPÍAS AL MERCADo"

En ningún lugar de la narrativa se alude a un posible vínculo del protagonista con los movimientos guerrilleros de los sesenta o setenta, pero la pertenencia de Izquierdo a la universidad de finales de los setenta sugiere el contacto con grupos de izquierda, como queda claro cuando el protagonista menciona los invitados a su boda: "Por mi lado, a la fiesta sólo fueron mi madre, mi hermana Eugenia, Hernán y otro amigo, Luis Camejo, que militaba en la ultraizquierda, se graduó de antropólogo, y terminó viviendo en Seattle, casado con una gringa y dedicado a la venta de pólizas 
de seguros médicos" (I80). Es muy significativo que en la economía del relato sepamos más sobre este "otro amigo" que sobre su confidente, Héctor, como si ese "otro" planteara un enigma más urgente que la presencia reconfortante de su amigo cercano. Sin embargo, además de las referencias a la militancia, creo que todos los motivos literarios posmodernos a que recurre la novela, y que discutiré más adelante, enfatizan no solo el fin del legado estético de la vanguardia, sino algo más significativo para el caso venezolano, una especie de interrupción de la reflexión crítica sobre la década de los sesenta y que coincide en Rating precisamente con la salida del protagonista - un intelectual en formación de la universidad y su ingreso a la televisión. Una breve revisión de un lúcido ensayo de Salvador Garmendia (1928-200I) sobre el periodo ayuda a entender las salidas personales y profesionales de muchos miembros de los grupos militantes de los sesenta y setenta y las consecuencias del fin de la vanguardia literaria.

En "Los sesenta: la disolución del compromiso" (I996), Salvador Garmendia esboza el escenario cultural y político de la década que unió los afanes revolucionarios, el desafío a las costumbres tradicionales y la búsqueda de un lenguaje libre. Para Garmendia, su generación, la de los jóvenes artistas venezolanos que en esa época tenían 30 años, asumió con intensidad los distintos legados estéticos e ideológicos que sacudieron a la comunidad intelectual latinoamericana. En el aspecto estético, El Techo de la Ballena (1961-1968), el colectivo artístico al que Garmendia perteneció, mostró una preferencia por los "movimientos nihilistas de comienzos de siglo en Europa, dadá y el surrealismo, lo mismo que otras manifestaciones más recientes de la vanguardia como el movimiento beatnik o el teatro del absurdo", aunque percibieron que la "desarticulación y redefinición del lenguaje" que encarnaban ambas corrientes no fueran compatibles con la propagación de una literatura de trinchera edificante y popular (597). Sin embargo, aunque sus búsquedas estéticas muchas veces no coincidieron con su militancia política, practicaron una "abierta solidaridad y más o menos encubierta logística con las organizaciones guerrilleras que aparecieron en distintas regiones del país por esos años", como queda claro en uno de los manifiestos publicados por el grupo: "Como los hombres que a esta hora se juegan a fusilazo limpio su destino en la Sierra, nosotros insistimos en juzgar nuestra existencia de escritores y artistas a coletazos y mordiscos" (599).

Más que hacer una evocación nostálgica de esos años, Garmendia elabora un balance crítico en el que da cuenta precisamente del abandono de la noción de "compromiso", entendido como la responsabilidad política del escritor con la sociedad, "aun en los ambientes que le fueron 
connaturales, las universidades" (596). Y en el caso de la lucha armada, el balance es también negativo, pero más que una derrota, se produjo una "baja" de los dirigentes que pasaron a ocupar cargos públicos (603). En suma, el legado político de los sesenta desembocó en una desagregación de quienes habían asumido la literatura comprometida y la lucha armada como únicas opciones: "La carrera del compromiso terminó, pues, sin ganadores pero tampoco hubo derrotados. La dignidad de la derrota no estaba en los planes. Tampoco quedó nadie para cerrar el balance ni hubo un expediente que guardar" (603). Esta suerte de deserción crítica y silencio en torno a los "años del compromiso" a que alude Garmendia explica pues la "despolitización" del protagonista de la novela y alude a la incapacidad de un campo literario o intelectual que "absorbiera" a los sujetos intelectuales militantes o en formación. ${ }^{4}$

Para Garmendia, el poder que enfrentan los escritores de los noventa, momento en que elabora su reflexión, no son ya los que enfrentaron quienes comenzaron a practicar la literatura en los sesenta - la derrocada dictadura de Marco Pérez Jiménez (1948-1958), las élites económicas y la moral burguesa - sino las compañías editoriales transnacionales, "que [son] hoy el nuevo capitán de industrias, el paladín de las cifras de venta que ha dejado de ser un ente vivo y comprobable [el editor] para disgregarse en lo abstracto" (596). Esta nueva situación del escritor amenaza "la literatura misma, aquélla a la que el tiempo preserva y protege como legado superior del hombre..." (596). En el capítulo "De las utopías al mercado" de Culturas híbridas, Néstor García Canclini discute de manera más amplia la transición a la que alude Garmendia en su ensayo. Allí afirma que las innovaciones artísticas de las vanguardias de los sesenta y setenta fueron perdiendo su carácter revolucionario y de afirmación de la autonomía del campo artístico y del artista a partir de los años ochenta por un "mercado en expansión" que comenzó a imponer sus propias formas de valoración a partir del consumo (55) en el que "las tendencias del mercado" sustituían al valor estético (6r).

La expulsión del protagonista de la biblioteca apunta también, además de a la disolución de la militancia, a esta transformación del campo literario asediado desde el exterior por la lógica del mercado..$^{5}$ Aun más, sugiere la ausencia de un contexto crítico que sirviera de contrapeso a su decisión de entrar a trabajar al canal de televisión o de un campo intelectual que le ofreciera otras salidas laborales. Aunado a esto, en la década de los ochenta América Latina experimentó un crecimiento acelerado de la cultura y medios audiovisuales que, en el caso de Venezuela, coincidió con la época "de la Venezuela saudita" - de los setenta y principios de los ochenta -, años en que una prosperidad económica sin 
paralelo "despertó un nuevo ímpeto materialista en la conciencia del venezolano" e instauró la telenovela como "la estética nacional durante la última etapa de la bonanza petrolera..." (Stanco II7). La manera en que Rating gestiona esta crisis de la cultura letrada, acelerada por la expansión de las industrias culturales, es a través de la articulación de diversos motivos literarios asociados con la posmodernidad, que se oponen a los postulados estéticos de la vanguardia: crisis de la universidad, fin de la literatura, intertextualidad y disolución del texto literario "puro". Discutiré brevemente cada uno de ellos en el contexto de la novela.

La universidad - como una de las sedes tradicionales de la ciudad letrada - estaba encargada de mantener el orden letrado a través de sus estrategias de ordenamiento, jerarquización, consagración y exclusión. ${ }^{6}$ En los años de las utopías estético-políticas de los sesenta y setenta, las universidades latinoamericanas participaron también del ideal de transformación del orden social, artístico y vital. La destitución de Izquierdo sugiere entonces un puritanismo que no encuadra con la idea de la universidad como espacio para el ejercicio de la innovación artística, la acción política y el amor libre y, por tanto, sugiere el comienzo de una crisis que terminará por consumarse con la implantación hegemónica de la cultura audiovisual y el mercado. Alejado así de la universidad y de un campo literario al que no llegó a ingresar, en los ochenta y acaso entrados los noventa, Izquierdo se entrega plenamente a la vida del canal de televisión. En esas décadas de prosperidad económica y de valores materialistas de la "Venezuela saudita", Manuel Izquierdo vive la nueva utopía de la era neoliberal: amoríos con actrices, fiestas, drogas (223). A finales de los noventa y a comienzos del milenio, llega la sobriedad, la introspección, el umbral de la vejez y el chavismo. En estos años ocurre el encuentro con el joven estudiante de Letras que lo pone de frente de nuevo con la universidad y la literatura después de su expulsión inicial.

Las referencias a la universidad del presente están dadas por la narración en primera persona del joven Manzanares quien relata su tránsito entre el mundo de la televisión y el espacio social de la universidad. El grupo de amigos con quienes comparte clases lee y escribe poesía. Emiliana, de quien Pablo está enamorado, rechaza explícitamente el medio televisivo, por lo que Pablo no puede decirle que trabaja para la televisión (9I). Cuando finalmente se atreve a revelárselo, Emiliana le responde: "Cómo puedes trabajar en la televisión y leer a César Vallejo" (193). Su amigo Randy, a quien "le fascina lo sórdido" (9I) y quiere escribir una "novela sobre mendigos" (77), marca, junto con la poesía, el otro límite de lo literario, el realismo sucio que se opone en su estética a los géneros televisivos tradicionales en su preferencia por el romance. Pareciera que el 
orden letrado está garantizado en el espacio cerrado de la academia, sin embargo, mientras Pablo se interna más en la dinámica del canal, ambos amigos comienzan a ser seducidos por el medio televisivo: Randy por la promesa de cercanía a las actrices de televisión y Emiliana por la promesa del éxito de Pablo. De manera que la universidad en tiempos posmodernos ya no produce consumidores exclusivamente cultos, porque el relativismo cultural posmoderno permite estos cruces y mezclas entro lo culto, lo popular y lo masivo (García Canclini 23). Ejemplo de lo cual es precisamente el tránsito de Manzanares de la universidad al canal de la televisión, que no se da, como en el caso de Izquierdo, por expulsión del ámbito letrado, sino por una seducción paulatina de la industria televisiva. Lo que me parece más definitivo es la manera en que el predominio de la cultura de la imagen comienza a contaminar los ámbitos más puros del canon literario resguardado por la universidad, como lo muestra la clase sobre Lezama Lima que están cursando Pablo y sus amigos: "Imagen y semejanza: poética de Lezama Lima, así se llama. El primer día de clase, el profesor nos dijo que no iba a dar bibliografía, que sólo leeríamos dos libros del poeta cubano y que todo lo demás lo conoceríamos a través de fotografías..." (48).

Esta "desaparición" del texto latinoamericano y de la lectura tradicional, sustituida por la lectura de imágenes, complementa la actitud posmoderna de Manuel Izquierdo, para quien la escritura literaria alcanzó su límite: “...sobre cualquier tema ya se escribieron todas las variantes, todas las mejores posibles versiones. Es un poco inútil y ridículo intentar escribir algo que valga la pena a estas alturas: la humanidad ya escribió todo lo que podía escribir" (6I). Y precisamente por esto, en una actitud claramente posmoderna, solo quedan las referencias intertextuales. En el primer encuentro de trabajo entre ambos, narrado con las acotaciones de los libretos de telenovela - lo cual apunta a la nueva hegemonía del código audiovisual - Izquierdo le sugiere al guionista novato que lea al escritor y guionista norteamericano Budd Schulberg (43).

Conviene detenerse en la referencia intertextual porque traslada al contexto latinoamericano la relación contenciosa entre arte e industria, entre la alta literatura norteamericana y los estudios hollywoodenses en las primeras décadas del siglo XX. En The Disenchanted (195I), Schulberg problematiza acremente la relación entre el escritor y la industria cinematográfica. La novela ficcionaliza de manera libre el breve periodo en que Schulberg colaboró con Scott Fitzgerald en la escritura de un guión cinematográfico a finales de los años treinta, años del declive final del autor, agobiado por las deudas, el alcohol y la falta de una nueva obra maestra que le devolviera el prestigio literario. En la novela de Schulberg, 
Manley Halliday, como es llamado Fitzgerald, siente un profundo desprecio por los libretistas asalariados a los que considera mercenarios (hacks), nada más alejado al tipo de arte que él ha hecho y el cual espera reanudar con lo que va a ganar en Hollywood. El sentimiento de degradación en la novela está alimentado no solo por el alcoholismo y la debilidad física del autor, sino también por la pérdida de la dignidad del artista libre. ${ }^{7}$

Las referencias intertextuales a Schulberg nos remiten a la subjetividad intelectual de Izquierdo que organiza su experiencia personal en la industria televisiva, "desde la literatura". Sin embargo, no se trata de un regreso simbólico a la Biblioteca Nacional de la juventud, sino de una confirmación del desplazamiento del letrado y la literatura en la sociedad contemporánea. Los intertextos amplían a escala global - nada más global que el universo hollywoodense - los temas de la novela: la escritura como forma de subsistencia, la marginalidad del escritor televisivo dentro de la industria y la ruptura de la hegemonía de las formas altas del arte, hacen más clara la disolución de la ciudad letrada; confirman además que la literatura se hace ahora enfrentada o articulada con los productos de la cultura de masas (Gutiérrez Mouat 73).

AFECTO Y MELODRAMA

Rating propone otra vía para ahondar en la subjetividad del protagonista, la de los afectos, en relación con los discursos patriarcales. La novela no elabora la relación afectiva de Manuel Izquierdo con Moraima, su amante universitaria, más allá de la referencia irónica al hecho de que ella haya logrado conservar su puesto en la biblioteca y él haya sido expulsado. Esa suerte de elipsis de las emociones vinculadas a la separación después de la expulsión anticipa las relaciones conflictivas del protagonista con las mujeres. En una charla con su amigo Hernán, que registra después en su diario, Izquierdo repasa su historia sentimental. Su matrimonio con Patricia, quien "podría haber sido la esposa y la madre ideal para cualquiera", fracasó porque él "no estaba preparado para un proyecto familiar" (I80). Más adelante, sin entrar en detalles, le confiesa a su amigo que su relación con la actriz Beatriz Centeno, "clausuró [su] experiencia afectiva" (I84). Sobre esta relación, la novela volverá en distintos momentos, en particular a la escena en que Izquierdo y Beatriz son arrestados en una fiesta con gente del canal de televisión por posesión de cocaína. Una nueva supresión de lo emocional se produce cuando Beatriz le dice, en medio del arresto, que está embarazada. Expuesto diariamente a los guiones de telenovela, familiarizado con todas las variantes del amor frustrado, Izquierdo, desde su posición de subjetividad racionalizadora, rechaza encuadrar su vida dentro de las fórmulas del melodrama y rechaza 
cualquier futuro con la actriz: "Sentí que estaba metido, atrapado, en una escena, en cualquier estúpida escena que yo podía haber escrito cualquier día, a cualquier hora, en cualquier estúpida telenovela. Y le dije entonces la frase. Estaba borracho y drogado. También tenía miedo. 'Tú no vas a convertir mi vida en una telenovela'. Se lo dije" (224).

Ahora que Izquierdo está en una etapa más reflexiva, emprende una revisión de sus emociones y dentro de ella la muerte de su madre ocupa un lugar central. Cuando se dispone a narrar la muerte de su madre, comienza con una frase que une la expulsión de la biblioteca, su ingreso a la industria y la conciencia de la madre de que allí comenzó un desvío: "A mi madre le sorprendió el salto de la Biblioteca Nacional a la telenovela" (I42). Y enseguida comienza la narración de los últimos días de su madre que intercala referencias a la telenovela en la que está trabajando en ese momento y las horas pasadas con ella en el hospital:

Era un capítulo de Primavera, lo habíamos escrito hacía casi un mes. Pero en ese momento, de pronto, todo lo que aparecía en la pantalla me resultó tan desmesurado. Viendo las imágenes en silencio se hacía más exorbitante el edificio. La protagonista lloraba como sólo se llora en las telenovelas. Me sentí vacío, ridículo. Miré a mi madre. Tenía la boca entreabierta. La luz del televisor iluminaba con un azul tenue su rostro ... Hasta que, de repente, el monitor que registra la presión arterial comenzó a sonar. Una luz roja parpadeó. En la tele pasaban una propaganda de una bebida achocolatada. Las enfermedades no tienen corte a comerciales. Mi madre comenzó a convulsionar. (II3)

¿No es este el locus de la intimidad contemporánea en el que las emociones íntimas se expresan en oposición, en contigüidad o a través de las narrativas de la cultura audiovisual? ${ }^{8}$ Del mismo modo que en la sociedad neoliberal globalizada, dominada por la economía de mercado, el texto literario se define como negación o adopción del texto audiovisual, los afectos en América Latina se modulan frente "al exceso sentimental" del melodrama (III). Más tarde, el protagonista regresa al momento en que tiene que comunicar la muerte de su madre a su hermana y concluye, después de una narración elíptica de su propio llanto: "Uno se gradúa de gente cuando pierde a su madre" (243; énfasis agregado). Me parece interesante que el relato omita la conversación con la hermana y el propio llanto porque esa formulación no verbal marca la diferencia entre las emociones que podrían definirse como un "material afectivo etiquetado y procesado por el lenguaje" (Peluffo 176), y el afecto que es, a decir de Brian Massumi, una "intensidad prepersonal' y no biográfica que remitía a la capacidad biopolítica de los cuerpos de afectar y ser afectados entre sí" 
(cit. en Peluffo ${ }^{176}$ ). ${ }^{9}$ Los afectos son entonces la posibilidad de apertura hacia el otro, que, en el caso de Rating, se hace claro en la cercanía entre el protagonista y su hermana, su madre, y más tarde el hijo, integrado a su nueva intimidad que comienza allí donde cierra la novela: "Mi hijo está sentado en el sofá, mirando la televisión. Yo ya sé que sólo se puede escribir a la velocidad de la muerte. Afuera llueve. Afuera siempre está lloviendo" (263; énfasis agregado). No es casual que el protagonista resuma sus experiencias con los verbos "graduarse" y "saber" porque los afectos se ofrecen como una apertura epistémica, dado que "... el sujeto cultural de la globalización neoliberal es epistémicamente afectivo, ya sea en afirmación o impugnación de la cultura dominante" (Reber IO3). La graduación universitaria malograda por la expulsión es aquí sustituida por una graduación personal lograda a partir de los afectos y que incluye la aceptación del dolor de la muerte de su madre y la aceptación de su condición de padre. Se trata de una crisis de la racionalidad letrada, pero también de una fractura en el ámbito personal del modelo patriarcal de masculinidad, que en la lectura política que propongo, era parte de la militancia de los sesenta y setenta, y en el presente, forma parte del discurso político bolivariano (Vera Rojas).

En este nuevo aprendizaje no letrado del protagonista, el melodrama es lo exterior a los afectos; las telenovelas - meticulosamente diseccionadas en su "lógica económica e industrial" y no en su consumo y usos (Martín-Barbero 62) - se vuelven un lugar de manipulación de las emociones: "La televisión vive del sufrimiento. Lo que importa es lo que se siente. Y si lo que se siente duele, entonces todavía importa más, es más auténtico. Eso fue lo primero que aprendí en este negocio" (Io9; énfasis agregado). Las emociones que provocan en los espectadores es su manera de intervenir en lo público. Cuando el jefe propone al protagonista la idea del reality show con indigentes influenciado por el contenido dramático de la telenovela, no oculta su ambición de modelar la realidad social de acuerdo al melodrama: "Quiero que te plantees este proyecto como si fuera una enorme telenovela, un gigantesco melodrama social. ¿No te parece un enorme desafío? ¡El país como una gran telenovela!” (II8). La evocación de la "escena nacional" no es disparatada, porque en las últimas tres décadas los medios de comunicación en América Latina, a través del uso político de las emociones, han suplantado al espacio público y es en ellos y a través de ellos que se hace la política. ${ }^{10}$

ESCENA NACIONAL

En un artículo reciente aparecido en el New York Times, ${ }^{\text {II }}$ el novelista y guionista de televisión venezolano Ibsen Martínez explica la conexión 
entre el melodrama y la realidad política latinoamericana. Para él, las telenovelas son "una metáfora dramatizada del populismo latinoamericano". Martínez sugiere que la trama más recurrente de aquellas no es tanto el amor no correspondido de la protagonista, como el mito de la "redención social", al estilo de Evita Perón. Las historias de redistribución de la riqueza entre los pobres, a lo Robin Hood, que narran muchas telenovelas, sin preguntarse sobre la manera en que esa riqueza fue creada, hacen pensar a Martínez en el chavismo.

El vínculo entre melodrama y populismo que menciona Martínez no es nuevo y responde a una conexión más profunda entre las "matrices populares" del melodrama (Herlinghaus), y el carácter altamente performativo y afectivo del populismo, como lo estudia Laclau (Kraniauskas). No me propongo ahondar en la relación entre estas dos formaciones discursivas, me interesa más bien explorar la manera en que el melodrama ha adquirido una alta dimensión social y política en tiempos de la llamada revolución bolivariana, como queda claro en el artículo de Martínez y, sobre todo, me interesa ver cómo el melodrama forma parte, en Rating, de una alegoría política más amplia. La forma que adquiere esta alegoría política en la novela es compleja: en primer lugar, se articula a partir de una asociación entre melodrama y chavismo a través del tema del amor, como sintagma común a ambos y, en segundo lugar, a partir del vínculo que se sugiere entre el régimen chavista y el cubano.

Mediante la afirmación de que "los afectos no son solo un asunto privado, sino que las lógicas emotivas ocupan un papel significativo en la constitución de la conciencia social y la construcción de imaginarios colectivos", Vera Rojas elabora un estudio minucioso de la importancia constitutiva del amor en el discurso político del chavismo (I79). Para ella, la "pasión romántica" se presenta en el chavismo como un "deber social" ( 178 ), como una "ética socialista" alimentada "por la fantasía de la 'suprema felicidad social"” (I70). Dicha ética suponía que:

... los otrora marginados por y del poder eran la representación de los nuevos sujetos nacionales que habían de llevar, a partir de la premisa del deber colectivo, del amor al prójimo y a sí mismo - en oposición al individualismo, egoísmo y materialismo del capitalismo -, las riendas del nuevo relato de la nación venezolana, del cual Chávez, en la encarnación del Estado, era la figura rectora. (178)

Para la crítica, las consecuencias de esta "identificación del amor con el socialismo" son la "división de la sociedad, la desestructuración de las precedentes instituciones de Estado, la implementación de comunas y la constitución del Estado comunal" (I69). En ese énfasis en el amor y las 
emociones - que universalizan una lucha que es eminentemente política -, el discurso chavista articula la lucha entre oprimidos y poderosos como un auténtico melodrama, en el sentido que el amor supremo por el líder que dirige al pueblo a la felicidad está siempre amenazado por las estratagemas de las élites. ${ }^{\mathrm{I} 2}$ Se trata esta de una de las últimas transformaciones ideológicas, políticas y retóricas del régimen chavista que no es ya, como exponía Fernando Coronil, la de "the unity of the nation as marriage of urban elite and the vital pueblo, of Santos Luzardo and Marisela", porque "Chávez is writing his own novel: it is now the history of the insurgency of the oppressed against the elite ... it is a struggle of the people against the elite" ("Magical History"). El "Estado comunal" que emerge de esta retórica política es en verdad una versión extrema del Estado moderno que impone su dominio biopolítico sobre los cuerpos de los sujetos. En diciembre de 20Io, la saliente Asamblea Nacional de Venezuela aprobó la Ley Orgánica del Poder Popular en la que se designa al Estado venezolano como un "Estado comunal", definido este como:

... una forma de organización político social, fundada en el Estado democrático y social de derecho y de justicia establecido en la Constitución de la República, en la cual el poder es ejercido directamente por el pueblo, con un modelo económico de propiedad social y de desarrollo endógeno sustentable, que permita alcanzar la suprema felicidad social de los venezolanos y venezolanas en la sociedad socialista. La célula fundamental de conformación del estado comunal es la Comuna. (Cit. en Brewer-Carías 2)

Me interesa explorar ahora la idea de que Rating formula un visión del Estado chavista, en su versión de un "Estado comunal", a partir de la metáfora del reality show con indigentes. El hilo conductor de esta lectura son las referencias a Cuba que, en principio, funcionan perfectamente en la lógica del relato, pero por su reiteración apuntan al contexto político fuera de ella. Como afirma Coronil, Cuba fue el modelo para Chávez en la definición de las funciones del Estado: "For Chávez, Cuba is the paradigm. A war of maneuver: taking over the state and revolutionizing society" ("Magical History").

Cuando Izquierdo repasa su historia laboral en el canal, elabora al mismo tiempo una historia de la implantación y desarrollo de las telenovelas en Venezuela. Repite de manera fabulada la historia bien conocida de la llegada de las primeras radionovelas cubanas y después la de los primeros exiliados de la revolución cubana que trajeron consigo nuevos libretos de melodramas radiales y televisivos. En particular, Izquierdo se refiere a Gerardo Lima, llegado a Venezuela el mismo año del 
comienzo de la Revolución. ${ }^{13}$ Como asistente de Lima, Izquierdo tenía que desempolvar los viejos libretos traídos por el cubano y sustituir las referencias antillanas por sus equivalentes venezolanos: "Donde diga guagua pones autobús, donde diga La Habana pones Caracas; donde diga pepilla pones chamita" (Iоо). Este trabajo de sustitución o adaptación del libreto original cubano tiene claras resonancias políticas en el momento actual: el chavismo aparece aquí como una adaptación, o mejor, una mala adaptación, "monstruosa", del modelo cubano a la realidad venezolana: "El proyecto de Quevedo es un injerto raro. Quiere ser y no ser un reality show y, al mismo tiempo, quiere ser y no ser una telenovela. En la televisión no funcionan esas dos mitades. Eso piensa Izquierdo. Lo único que producen son monstruos" (I3I).

En esta lectura de la adaptación venezolana del guión político cubano sobre la "toma del Estado" cobra mucho sentido la inclusión en las primeras páginas de la novela de la entrada del diccionario de la Real Academia de la Lengua Española de la palabra intervención. Cuando Rafael Quevedo le explica por primera vez su idea de un reality show al principiante Manzanares le dice que la idea es meter "a seis o siete mendigos, loquitos de la calle, recogelatas ... en una casa para filmarlos durante un mes, las veinticuatro horas del día" (I7), y añade más adelante: "Obviamente, nosotros vamos a intervenir lo que suceda en el programa" (I7). Después de leer las acepciones, Manzanares concluye que ninguna se aplica al programa y que "la televisión funciona con otro diccionario" (I9). Sin embargo, en la alegoría política que va delineando el relato, algunas de las acepciones transcritas adquieren mayor relevancia: "Dicho de una autoridad: Dirigir, limitar o suspender el libre ejercicio de actividades o funciones..." (I8).

La idea de confinamiento e intervención que supone el proyecto del reality show encarna una de las imágenes de mayor violencia simbólica de la novela porque sugiere ese espacio que para Agamben es el verdadero locus del Estado moderno: el campo de concentración. Para él, allí se consuma la soberanía del Estado - a través de la instauración del Estado de excepción - y, al mismo tiempo, se produce la subjetivación que convierte al ser humano (la "nuda vida" o el "hombre sagrado", como también lo llama) en ciudadano del Estado (Homo sacer). La novela no puede ser más explícita en cuanto a esa voluntad biopolítica de confinamiento e intervención de los cuerpos de indigentes, esa humanidad desechable, que habita en los márgenes del Estado y cuyos cuerpos se intenta confinar. Una de las primeras responsabilidades de Manzanares en su trabajo en el canal será precisamente buscar indigentes para convencerlos de participar en el programa. Con la ayuda de un tío expolicía de Randy, recorre ciudades en 
ruinas, construidas con materiales de deshecho debajo de puentes y habitadas por sombras y seres inconscientes que viven una humanidad abyecta (79; I08).

En las referencias políticas de la novela, sin embargo, la adaptación del modelo cubano por parte de la república bolivariana, no explica enteramente la emergencia de ese Estado que aspira al confinamiento de las masas. La referencia a la casa donde se va a llevar a cabo el reality show sugiere una hipótesis anclada en la historia política venezolana. En una visita a la casa donde serán las grabaciones, Manzanares observa:

Es una vieja edificación, con una arquitectura de los años cincuenta. La ubicación es perfecta, en una zona residencial, con cierto abolengo, pero venida a menos ... Todo el techo había sido construido con madera de vera, traída especialmente del Amazonas. De la piscina se encargó un técnico alemán, quien viajó un par de veces de Hamburgo a Caracas. Eran los tiempos de la dictadura de Jiménez. (I49)

Se ha señalado ya el vínculo entre el gobierno de Chávez y la dictadura de Marco Pérez Jiménez (1948-1958), sobre todo en las semejanzas externas en cuanto al carácter militar de ambos regímenes, sus formas de acceso al poder y, en particular, su rehabilitación política después de un golpe de estado (Mendoza Angulo I6-I7). Sin embargo, Coronil en su excelente libro The Magical State ha explicado la manera en que la dictadura de Pérez Jiménez fundó el petro-estado moderno venezolano en el sentido en que logró unir discursivamente el cuerpo natural de la nación - sus riquezas petroleras - y el cuerpo social que se volvió su beneficiario natural, pero al mismo tiempo promovió la desmovilización social porque el Estado se volvió el representante directo de las masas (I68).

La metáfora de la casa-nación en la novela explica entonces las raíces históricas no solo del chavismo sino también del conflictivo Estado moderno venezolano y su intervención en la vida del cuerpo de la nación. La alegoría política de Barrera Tyszka ofrece una lectura compleja para el presente caótico y polarizado de la Venezuela bolivariana, equipara el régimen chavista con lo que Agamben llama, siguiendo a Guy Debord, la nueva "forma del Estado": el Estado democrático-espectacular ("Marginal Notes" 84), aquel que tiene a los pueblos como espectadores y como ciudadanos y el cual vacía "tradiciones, creencias, ideologías, religiones, identidades y comunidades" (84, traducción mía) y las sustituye por el lenguaje del espectáculo (82). Es por eso que en la novela, medios y Estado se benefician del confinamiento de las masas: 
El vicepresidente ejecutivo [del canal] me contó que estaban negociando con las autoridades y que el propio gobierno central se había mostrado interesado en participar en el programa. Ya había toda una mesa de negociaciones para que, de pronto, el próximo domingo en la noche, el propio presidente de la República llamara por teléfono a la casa y hablara con los concursantes. Eso lo propuso el propio presidente, me aseguró el señor Salcedo. Ya verás. Esto va a ser un éxito. (26r)

La vuelta de tuerca final de este "monstruo" que es el reality show con los damnificados por las lluvias (ante la imposibilidad de firmar contratos con los indigentes) es cuando los participantes seleccionados, a quienes se les han asignado los papeles diseñados por Izquierdo y Manzanares y han recibido un breve curso de actuación, se rebelan el segundo día de filmación ante las noticias de que el rating fue bajísimo el primer día y los rumores de que cancelen el programa y se queden sin la posibilidad de ganar la casa prometida. Así que deciden orquestar una denuncia de la falsedad de todo el proyecto en vivo: "Esto no es parte del programa. Esto no es en serio. Nosotros queremos decir la verdad" (256; énfasis en el original). Cada uno cuenta su propia verdad frente a las cámaras y parecen haber desmotado la farsa televisiva. Sin sospecharlo, los participantes han elevado el rating del programa con esa especie de motín orquestado. Los ejecutivos del canal llaman inmediatamente al joven Manzanares y le dicen: "Lo que ocurrió anoche fue extraordinario. Descubrimos que ése es el programa que tenemos que hacer" (259).

La novela enuncia entonces un doble confinamiento: el de los sujetos colectivos cuyas demandas solo pueden ser articuladas por el medio televisivo y el confinamiento de los espectadores que integran el espectáculo a su intimidad personal. Se trata pues de una recreación oblicua del Estado comunal de la revolución bolivariana y, al mismo tiempo, una alusión al Estado moderno, en su versión extrema, la del Estado espectacular-democrático (Agamben, "Marginal Notes"). Ambas formaciones políticas no son contradictorias dado que Chávez fracasó en su intento de sustraer el Estado venezolano, siguiendo el modelo cubano, de la economía neoliberal global, como explica Coronil: "Chávez has taken over the state, but cannot so easily revolutionize society. He faces the challenge that all nationalist projects confront in the Global South: the contradiction or tension between national conditions of state legitimacy and the international conditions of capital accumulation" ("Magical History"). En suma, Rating, a partir de la alegoría política que acabo de exponer, propone una nueva lectura de la historia reciente venezolana. El actual Estado comunal no tiene su origen en el caudillismo decimonónico, 
ni en los movimientos guerrilleros y estudiantiles de los años sesenta y setenta - aunque haya adoptado su discurso -, sino en la conformación misma del Estado moderno con raíces globales y nacionales.

EL RETIRO DE LA ESCRITURA

La universidad y la industria televisiva son pues dos modos desiguales en los que se encarna lo público en la novela. La primera aparece reducida en su capacidad de formar sujetos que sean capaces de ejercer la "racionalización de las esferas públicas" que se espera del discurso letrado (Herlinghaus 32). El melodrama, en cambio, género predilecto de las industrias audiovisuales, se vuelve un auténtico discurso público por la capacidad que tiene para articular las sensibilidades contemporáneas y, al mismo tiempo, porque desde hace décadas los medios se han vuelto el lugar mismo de la política. Expulsado de la primera, y a punto de renunciar a la industria televisiva, el protagonista de Rating decide replegarse al ámbito de lo privado. Es allí donde despliega su verdadero gesto literario, la escritura de su diario personal:

Ahora me doy cuenta de que ya no puedo cambiar nada de lo que fui. Ahora sólo puedo escribirlo. Quizás la escritura es la única oportunidad que tengo de ser distinto. Probablemente, esta versión de mí mismo sea mucho mejor que mi propia vida ... Tal vez hice algunas cosas de las que ahora me arrepiento, pero también es cierto que tenía un ánimo, una fuerza, un ímpetu que ahora extraño, envidio. Tenía futuro. La lógica de la vida es mezquina. Cuando era un inconsciente, me gasté la mayor parte del tiempo que tenía. Ahora, que por fin comprendo mejor tantas cosas, que por fin sé qué quiero y qué puedo esperar de mí y de los demás, ahora lo único que puedo hacer es despedirme. (34)

Miguel Gomes ha visto muy bien cómo la novelística venezolana reciente desemboca muchas veces en una introspección y una melancolía precipitadas por el desencanto ante "el derrumbe material y el caos moral del país" ("El cuento venezolano" 36). En el caso de Rating, la referencia a la melancolía es muy pertinente porque explica muchas de las actitudes del protagonista. La sensación de envejecimiento repentino, el desinterés por su entorno, su incapacidad de relacionarse con los demás y la percepción crítica de sí mismo apuntan a la condición melancólica. En la definición clásica de Freud, la melancolía tiene como origen una "pérdida desconocida" (245). La naturaleza de la pérdida que sufrió el protagonista de Rating es múltiple: el fin del horizonte de la utopía revolucionaria y estética (que ha estudiado muy bien Bruno Bosteels en el contexto latinoamericano), el fracaso de los sueños juveniles de escritor, la ausencia 
de un campo literario al cual integrarse después de la expulsión, la construcción de una masculinidad machista que canceló su vida afectiva, la devastación del entorno social por la crisis y el chavismo, la pérdida del espacio público dominado ahora por los medios. La condición melancólica resultante de estas pérdidas forma parte de una tradición de la literatura venezolana desde la década de los sesenta, como sostiene Iraida Casique, en la que la noción de fracaso permea un imaginario literario donde abundan los sujetos, y sobre todo los sujetos intelectuales excluidos, "que niegan la posibilidad de participación y de todo proyecto político" (605).

La soledad final en la que el protagonista de Rating escribe su diario personal supone, en mi opinión, un nuevo entendimiento del campo literario venezolano: no se trata solo de la crisis de participación que menciona Casique, sino más bien de la soledad resultante del retiro del apoyo del Estado bolivariano a los creadores "de oposición" y de la constitución de la escritura en "islas" a consecuencia de la disolución del campo literario y la hegemonía del mercado, como lo entiende Josefina Ludmer para el contexto latinoamericano. Sin embargo, desde esta soledad creativa se reafirma el compromiso con la escritura misma y con la reflexión crítica sobre el presente y el pasado. Así Rating participa de la intensa reflexión que actualmente ocupa a narradores y críticos venezolanos ante lo que se percibe como un intento de ocultamiento, olvido y tergiversación de los últimos cincuenta años de la historia de Venezuela por parte del régimen bolivariano (Silva Beauregard). Rating, no obstante, emprende esa reflexión crítica desde supuestos más amplios que incluyen un examen de la naturaleza del régimen bolivariano más allá de las acusaciones de anacrónico, una indagación en la historia del campo literario venezolano y del estado de la literatura en el contexto de la sociedad audiovisual, y una exploración de la subjetividad de esa generación que vivió los "años del compromiso" y de la compleja transición de la "democracia decadente" al régimen autoritario actual (Pacheco 27). Un ejercicio crítico y creativo que, sin duda, confirma la vitalidad actual de la literatura venezolana.

Providence College

NOTAS

I Gustavo Guerrero parte de la observación inicial de Miguel Gomes de que en la narrativa venezolana reciente se articula una "red de significados sociales" de manera alegórica ("Modernidad" 827). 
2 Para lecturas más detalladas de las obras mencionadas, véanse, para el tema de la revisión histórica, Silva Beauregard y Pacheco ("In/Visibilidad"); y para la estética transnacional en la literatura de escritores jóvenes, Brown.

3 Para una análisis detallado y perspicaz del campo literario latinoamericano y su relación con el ámbito social del momento, véase Sarlo, "Strategies of the Literary”. Allí la crítica argentina se refiere a la novela El libro de Manuel de Julio Cortázar como la obra emblemática de la década de los setenta en la que muchos lectores jóvenes aprendieron "the dynamics of the relation between literature and politics"(238). No me parece casual que en la novela de Barrera Tyszka el nombre del protagonista expulsado prematuramente de la ciudad letrada sea precisamente Manuel.

4 Ana Teresa Torres ha notado muy bien cómo la tradición literaria venezolana no ha logrado constituir un campo literario "articulador": “Más allá de las admiraciones muy personalizadas, creo percibir una implícita reticencia de los escritores venezolanos a sentirse parte de un cuerpo común, a conocerlo, a dialogarlo, a interpelarlo y a reconocerse en alguna de sus articulaciones" (918).

5 Josefina Ludmer delinea las transformaciones de la literatura en el contexto neoliberal, que establece un quiebre frente a la literatura de los sesenta y los setenta. A esta nueva literatura la llama "literaturas posautónomas". Se trata de obras que "aparecen como literatura pero no se las puede leer con criterios o categorías literarias como autor, obra, estilo, escritura, texto y sentido" (I5O), porque el "campo literario" ha desaparecido y se han borrado las "identidades literarias” y la lucha por el poder literario características de la autonomía de la literatura (154). Los nuevos registros literarios "salen de la literatura y entran a la 'realidad' y a lo cotidiano, a la realidad de lo cotidiano, y lo cotidiano es la TV y los medios, los blogs, el e-mail, Internet" (I5I).

6 Ángel Rama formuló la noción de “ciudad letrada” para delinear el papel de la actividad letrada - y sus practicantes - en la conformación del poder político desde el periodo colonial hasta el comienzo de la modernidad en América Latina. En este último periodo, la universidad, considerada "siempre la joya más preciosa de la ciudad letrada”, era una de las vías más comunes de acceso a esta (57).

7 Otra referencia intertextual importante en la novela son la serie de cuentos de Pat Hobby de Scott Fitzgerald (The Pat Hobby Stories, 1962), que refuerzan la idea de la marginalidad del guionista en el mundo brutal de los estudios de cine.

8 Ludmer define esta experiencia de la inserción de los medios, la televisión y el melodrama en la vida cotidiana como lo "íntimopúblico", es decir, la manera en que la temporalidad del melodrama confluye con la temporalidad de la vida 
cotidiana y define una nueva manera de estar unidos públicamente, desde la intimidad y familiaridad $\left(4 \mathrm{O}^{-} 4 \mathrm{I}\right)$.

9 Para una elaboración más detallada de la diferencia entre emoción y afecto, véase Beasley-Murray, en particular el capítulo tres.

Io En "Estética y pospolítica", Beatriz Sarlo explora la "espesa red de préstamos entre el discurso político y los mass media" a través de ciertas imágenes de la campaña presidencial de Fujimori en r99r (3IO), y concluye: "Si la política debe contrastar opciones (es más: la política produce las opciones), la técnica [los mass-media] sin política se presenta como única salida" (3I4).

II El artículo de Martínez es una respuesta a uno de Nicolás Maduro ("Venezuela: A Call for Peace”), en el que el sucesor de Hugo Chávez defiende la actuación de su gobierno en las protestas estudiantiles.

I2 En uno de sus comentarios sobre el melodrama, el protagonista de Rating dice: "La audiencia en el fondo, sólo quiere ver las dificultades del amor ... La gente enciende la pantalla y sintoniza una telenovela para ver obstáculos, impedimentos, maldades" (I86).

I3 El protagonista hace una descripción física de su jefe que juega con el parecido a Fidel Castro (123). Por otro lado, es importante mencionar que las referencias a la llegada de las telenovelas cubanas a Venezuela aluden a la historia de Goar Mestre, el empresario cubano que instaló canales de televisión en varios países de América Latina y así transformó un campo intelectual que estaba marcado por el compromiso literario (Varela 760).

\section{OBRAS CITADAS}

A G a b en, gi orgio. Homo Sacer: Sovereign Power and Bare Life. Trad. Daniel Heller-Roazen. Standford: Stanford UP, 1998.

—. "Marginal Notes on the Commentaries on the Society of the Spectacle". Means without End: Notes on Politics. Trad. Vicenzo Binetti y Cesare Casarino. Minneapolis: U of Minnesota P, 2000.

BARRERA TYSZKa, ALBERT 0. Rating. Barcelona: Anagrama, 20 II.

beasley-murray, jon. Posthegemony: Political Theory in Latin America.

Minneapolis: $U$ of Minnesota $P, 201$.

B os te els, B Run o. Marx and Freud in Latin America: Politics, Psychoanalysis, and Religion in Times of Terror. Londres: Verso, 2012.

BRewer-Carías, A l lan R. "Sobre el Poder Popular y el Estado Comunal en Venezuela". 3 julio 20I4. <www.allanbrewercarias.com>.

B Row N, к A т IE. "Blue label/Etiqueta azul de Eduardo Sánchez Rugeles: una historia que cruza fronteras". Anales de Literatura Hispanoamericana 42 (2013): 15-26. CASIQUE, IRAIDA. "Modelos de intelectualidad marginal en la narrativa de los sesenta y setenta". Pacheco, Barrera Linares y González Stephan 605-624. 
C ORONIL, FER NAN Do. The Magical State: Nature, Money, and Modernity in Venezuela. Chicago: The U of Chicago P, 1997.

—. "Magical History: What's Left of Chávez?" 5 mayo 2014 $<$ http://lanic.utexas.edu/project/etext/llilas/vrp/coronil.pdf>.

F RE UD, SIG MUN D. "Mourning and Melancholia". The Standard Edition of the Complete Psychological Works of Sigmund Freud, Volume XIV (1914-1916). Londres: The Hogarth Press and the Psycho-Analytic Institute, I917. 237-258. GARCÍA CANCLINI, NÉST OR. Culturas híbridas: Estrategias para entrar y salir de la modernidad. México: Grijalbo, I990.

GARMEN Di A, SALVAD OR. “Los sesenta: la disolución del compromiso”. Pacheco, Barrera Linares y González Stephan 593-603.

GOMES, MigUEL. "Modernidad y abyección en la nueva narrativa venezolana". Revista Iberoamericana 76.232-233 (2010): 821-836.

—. "El cuento venezolano entre la mundialización y el colapso interno". Cuadernos hispanoamericanos 753 (2013): $35^{-4} 4$.

GUERRERo, GUSTAVo. "Narrativa venezolana contemporánea: problemas, tendencias y transformaciones del campo literario". Cuadernos Hispanoamericanos 753 (2013): 13-23.

GutiérRez mouat, Ricardo. "The Modern Novel, the Media, and Mass Culture in Latin America”. Latin American Literature and Mass Media. Eds. Edmundo PazSoldán y Debra Castillo. New York: Garland Publishing, 200I. 71-10o.

HERL INGHAUS, HER MAN N, E D. Narraciones anacrónicas de la modernidad:

Melodrama e intermedialidad en América Latina. Santiago: Cuarto Propio, 2002.

KOZAK, GISELA. "Políticas culturales y hegemonía en la revolución bolivariana:

'Ética y estética socialistas'”. La literatura asediada: revoluciones políticas, culturales y sociales. Caracas: Universidad Central de Venezuela, 2012.

KRAN IAUS KAS, J OHN. "Hacia una crítica de la política pura: apuntes sobre La razón populista de Ernesto Laclau". Estudios I6.3I (2008): 71-83.

L ud m e r, jos e fina. Aquí América latina: Una especulación. Buenos Aires: Eterna Cadencia, 2010.

madur 0, nicolás. "Venezuela: A Call for Peace”. New York Times a abril 2014

MART Ín-BARBERo, JESÚs. "La telenovela desde el reconocimiento y la anacronía". Herlinghaus $6 \mathrm{I}^{-} 77$.

m A RT ín EZ, i BSE n. “Chaos, Chavismo, and Telenovelas.” New York Times 8 abril 2OI4.

MEN D Z a An Gulo, José. Venezuela destino incierto. Para comprender lo que pasa hoy en el país. Mérida: Universidad de Los Andes / Vicerrectorado Académico, 2005 .

MORAÑA, MABEL E IGNACIO SÁNCHEZ PRADO, EDS. El lenguaje de las emociones: afecto y cultura en América Latina. Madrid: Iberoamericana, 2012 
PACHECO, CARLOS, LUIS BARRERA LINARES Y BEATRIZ GONZÁLEZ STEPHAN, C O O R D. Nación y literatura: Itinerarios de la palabra escrita en la cultura venezolana. Caracas: Fundación Bigott/ Equinoccio/ Banesco, 2006.

PACHECo, CARLos. "In/Visibilidad de la novela venezolana (1990-2010)". Cuadernos Hispanoamericanos 753 (2013): 25-34.

PELUFFO, ANA. "Emoción, afectividad y sentimiento en la construcción del pasado setentista”. Moraña y Sánchez Prado I73-190.

REBER, DIERDRA. "La afectividad epistémica: el sentimiento como conocimiento en El secreto de sus ojos y La mujer sin cabeza”. Moraña y Sánchez Prado 93-I05.

SARLO, BEATRIz. "Estética y pospolítica. Un recorrido de Fujimori a la guerra del Golfo". Cultura y pospolítica. El debate sobre la modernidad en América Latina. Comp. Néstor García Canclini. México: CONACULTA, I995· 309-324.

- . "Strategies of the Literary Imagination". Fear at the Edge: State Terror and Resistance in Latin America. Eds. Juan E. Corradi, Patricia Weiss Fagen y Manuel Antonio Garretón. Berkeley: U California P, 1992. 236-249.

RAMA, ÁnGEL. The Lettered City. Trad. John Charles Chasteen. Durham: Duke UP, 1996.

Silva BEAUREGARD, PAULETtE. "Novela e imaginación pública en la Venezuela actual: el regreso de viejos fantasmas (I)”. Espéculo: Revista de Estudios Literarios 15.48 (2OII).

ST An C 0, E LDA. "Caracas en nuestra (tele)novela de todas las noches: Mujeres de un solo zarcillo y la novela telenovelizada". Hispanic Review 79.I (2OII): II5-I34.

TORRES, ANA TERESA. "Cuando la literatura venezolana entró en el siglo XXI". Pacheco, Barrera Linares y González Stephan 91 ${ }^{-} 925$.

VARE L A, M IR T A. "Intelectuales y medios de comunicación”. Historia de los intelectuales en América Latina II: Los avatares de la "ciudad letrada" en el siglo $X X$. Ed. Carlos Altamirano. Buenos Aires: Katz, 2010.

VERA ROJAS, MARÍA TERESA. "Humanismo, heteronormatividad y homofobia en el socialismo del siglo XXI: el amor como consigna". Resentir lo queer en América Latina: diálogos desde/con el Sur. Eds. Diego Falconí Trávez, Santiago Castellanos y María Amelia Viteri. Barcelona: Egales, 2014. 